\title{
Pharmacokinetic evaluation of D-ribose after oral and intravenous administration to healthy rabbits
}

This article was published in the following Dove Press journal:

Clinical Pharmacology:Advances and Applications

\author{
Karem H Alzoubi' \\ Zuhair Bani Ismail ${ }^{2}$ \\ Mohamed K AL-Essa ${ }^{3}$ \\ Osama Y Alshogran' \\ Reem F Abutayeh ${ }^{4}$ \\ Nareman Abu-Baker ${ }^{5}$ \\ 'Department of Clinical Pharmacy, \\ Faculty of Pharmacy, Jordan University \\ of Science and Technology, Irbid, \\ Jordan; ${ }^{2}$ Department of Veterinary \\ Clinical Sciences, Faculty of Veterinary \\ Medicine, Jordan University of \\ Science and Technology, Irbid, \\ Jordan; ${ }^{3}$ Department of Physiology, \\ Faculty of Medicine, University of \\ Jordan, Amman, Jordan; ${ }^{4}$ Department \\ of Medicinal Chemistry and \\ Phytochemistry, Applied Science \\ Private University, Amman, Jordan; \\ ${ }^{5}$ Philadelphia Biomedical Products \\ Development Center, Amman, Jordan
}

Introduction: This study explored D-ribose pharmacokinetics after intravenous (IV) and oral administration to healthy rabbits.

Materials and methods: D-ribose was administered once as $420 \mathrm{mg} / \mathrm{kg}(\mathrm{N}=4)$ or $840 \mathrm{mg} / \mathrm{kg}$ $(\mathrm{N}=6)$ dose intravenously, or as an oral dose of $420 \mathrm{mg} / \mathrm{kg}(\mathrm{N}=3)$ or $840 \mathrm{mg} / \mathrm{kg}(\mathrm{N}=3)$. Serum was obtained at various time points, up to 210 minutes after administration. Urine was also collected after IV administration. Pharmacokinetic parameters were determined from drug concentration-time data using Kinetica software.

Results: The findings showed that D-ribose follows a dose-dependent kinetic profile. With doubling the IV dose, $\mathrm{AUC}_{\text {total }}$ was significantly increased by threefold, while the clearance was decreased by $44 \%$. The half-life was 1.7 -fold longer at the higher dose. Similar nonsignificant trends were also observed at oral administration. D-ribose was rapidly absorbed $\left(\mathrm{T}_{\max }=36-44\right.$ minutes) and rapidly disappeared from plasma (within $<140$ minutes). Additionally, D-ribose was partially (18-37.5\%) recovered from urine.

Conclusion: Collectively, D-ribose showed a dose-dependent kinetic profile, where parameters change according to dosing levels. D-ribose clearance seems to follow first-order kinetics at low dose. Thereafter, elimination systems are saturated, and elimination continues in a fast manner. Urine recovery was partial, which could be attributed to the several metabolic pathways that pentose can undergo.

Keywords: D-ribose, single dose, pharmacokinetics, rabbits, oral, intravenous

\section{Introduction}

D-ribose is a natural pentose monosaccharide and is a key constituent of newly generated adenosine triphosphate (ATP), guanosine triphosphate (GTP), RNA, DNA, and riboflavin. ${ }^{1}$ Pharmacological effects of $\mathrm{D}$-ribose and its physiological relation on certain systems have been reported. The beneficial effect on cardiac muscle has been studied in many animal models. These studies have shown a potential protective effect on the heart, by restoring cellular ATP and cardiomyocyte function as in cases of hypoxia. ${ }^{2-4}$ Clinically, administration of D-ribose as $3.3 \mathrm{mg} / \mathrm{kg} / \mathrm{min}$ intravenously for 30 minutes to 17 patients with coronary artery disease enhanced the identification ischemic myocardium tissue..$^{5}$ More recently, it has been reported that when patients $(n=11)$ with diastolic heart failure are given oral D-ribose ( $5 \mathrm{~g} /$ dose $)$ for 6 weeks, a trend toward improvement in tissue Doppler velocity was observed in $64 \%$ of patients suggesting improving diastolic function. ${ }^{6}$ Other studies have shown that D-ribose protects against ischemia-induced renal injury in rats ${ }^{7}$ and from cisplatin-induced nephrotoxicity in
Correspondence: Karem H Alzoubi Department of Clinical Pharmacy, Faculty of Pharmacy, Jordan University of Science and Technology, Amman-Ramtha Street, Irbid 22110 , Jordan

Tel +96227201000 (ext 2352I)

Fax +96227201075

Email khalzoubi@just.edu.jo 
mice, ${ }^{8}$ and ameliorates the clinical symptoms in fibromyalgia and fatigue syndrome patients at $5 \mathrm{~g}$ dose given three times daily. ${ }^{9}, 10$ It has been recently shown that administration of 420 $\mathrm{mg} / \mathrm{kg}$ D-ribose intravenously to rabbits for 28 days did not induce clinical, behavioral, hematological, pathological, and histological toxic effects. ${ }^{11}$ Oral administration of D-ribose to healthy people was tolerable with instances of diarrhea occurring at doses higher than $200 \mathrm{mg} / \mathrm{kg} / \mathrm{h}{ }^{12}$

Limited pharmacokinetics data are available about D-ribose. Oral administration of a single dose of D-ribose solution at $2.5,5$, or $10 \mathrm{~g}$ to healthy individuals was well tolerated and revealed that D-ribose is rapidly absorbed with an increase in the exposure of more than proportionality with increasing dose. ${ }^{13}$ The percentage of dose excreted in the urine ranged from $4.15 \%$ to $7.2 \% .{ }^{13}$ At the doses up to 200 $\mathrm{mg} / \mathrm{kg} / \mathrm{h}$, D-ribose absorption in humans was determined to be $87.8-99.8 \%$ with minimal first-pass effect. ${ }^{12}$ The latter study also showed that the urinary loss of D-ribose was $23 \%$ of $222 \mathrm{mg} / \mathrm{kg} / \mathrm{h}$ dose that was administered intravenously over 5 hours. ${ }^{12}$ This may indicate larger loss at the high dose of administration.

Herein, we assessed the preclinical pharmacokinetics of D-ribose in rabbits after oral and intravenous (IV) administration of two different doses. These routes have been chosen because they are the proposed routes for administration to humans.

\section{Materials and methods}

\section{Test material}

Natural D-ribose $\left(\mathrm{C}_{5} \mathrm{H}_{10} \mathrm{O}_{5}\right.$; molecular weight: $150.13 \mathrm{~g} / \mathrm{mol}$, $>98 \%$ purity, chemical abstracts service number: 50-69-1) was obtained from Heartland Biosciences (Minneapolis, MN, USA) as a spherical white powder. The substance was dissolved in water for injection in the concentration of $8.4 \%$. The $8.4 \%$ solution was diluted in $1.63 \%$ sodium chloride solution to reach the concentration of test substances of $4.2 \%$. The preparation was made right before the treatment. The final concentrations of the D-ribose in the test substance were $8.4 \%$ and $4.2 \%$.

\section{Animals}

Healthy adult male V-line (Valencia) rabbits with a weight of $2-2.5 \mathrm{~kg}$ were obtained from the Alexandria University, Alexandria, Egypt. Rabbits were selected because they were widely used for pharmacokinetic testing. A total of 16 rabbits were used in the study, which were randomly distributed based on body weights into two groups. Group I (10 rabbits) was used for IV experiments and group II (6 rabbits) was used for oral D-ribose administration. Each animal was administered $10 \mathrm{~mL} / \mathrm{kg}$ of the prepared test substance to obtain final D-ribose doses of 420 or 840 $\mathrm{mg} / \mathrm{kg}$. Four rabbits received $420 \mathrm{mg} / \mathrm{kg}$ IV dose, while six rabbits were administered $840 \mathrm{mg} / \mathrm{kg}$ D-ribose. Group II encompassed three animals within each subgroup. All experimental protocols were approved by the Animal Care and Use Committee of Jordan University of Science and Technology. Animals' welfare was insured via following the Institutional Animal Care and Use Committee Guidebook. ${ }^{14}$

Animals were housed individually in cages and kept in one room that was well-ventilated ( $>10$ air changes per hour) with $100 \%$ fresh air (no air circulation). A 12-hour light/12hour dark photoperiod was maintained. Room temperature and relative humidity were set to be maintained at $22 \pm 3^{\circ} \mathrm{C}$ and $30-70 \%$, respectively. Animals were acclimatized for 1 week before conducting the study.

\section{Administration route and procedure}

Rabbits were fasted for $\sim 12$ hours prior to dosing the substance, with water being freely offered ad libitum in bottles. D-ribose was administered either IV to group I as a solution by slow injection over 5-10 minutes in the ear vein using 23-25 gauge sterile disposable needles or by oral gavage to group II.

Using $25 \mathrm{G}$ syringes, blood samples were collected from the ear veins in volumes of $1.5-2.5 \mathrm{~mL}$ at $0,12,24,36,48$, $60,80,100,120,150,180$, and 210 minutes of D-ribose administration. Feed and water were provided after the end of blood collection. The blood was centrifuged and serum was separated and divided over 3-4 Eppendorf tubes $(\sim 300$ $\mu \mathrm{L}$ in each) and stored at $-20^{\circ} \mathrm{C}$ until analysis.

Urine samples were also collected for the two subgroups of rabbits that received $840 \mathrm{mg} / \mathrm{kg}$ and $420 \mathrm{mg} / \mathrm{kg}$ of D-ribose intravenously. Urine collection time periods were at $0-60$, 61-120, 121-180, and 181-210 minutes. Samples were divided into $3-5$ aliquots and frozen until the assay.

\section{Serum and urine bioanalysis}

A simple assay method was adopted from Roe and Rice ${ }^{15}$ with minor modifications to quantify D-ribose in serum and urine samples. The assay is based on the formation of furfural from D-ribose in $83 \%$ acetic acid containing thiourea at $70^{\circ} \mathrm{C}$, and the reaction of the furfural with $\mathrm{p}$-bromoaniline acetate to form a pink-colored product. The product was measured using a UV- spectrophotometer (Shimadzu UV-1800; Shimadzu Corporation, Kyoto, Japan) at $515 \mathrm{~nm}$.

The spectrophotometric method was partially validated for both biological matrices, serum and urine, prior to running 
the animals' authentic samples. Calibration curves were constructed at eight concentration levels ranging from 1.5625 to $200 \mu \mathrm{g} / \mathrm{mL}$ using $200 \mu \mathrm{L}$ serum or urine samples. Linear regression analysis was used to fit the data. The accuracy and precision were assessed by analysis of quality control (QC) samples. Six replicates of low QC (LQC $=5 \mu \mathrm{g} / \mathrm{mL})$, medium QC $(\mathrm{MQC}=15 \mu \mathrm{g} / \mathrm{mL})$, or high QC $(\mathrm{LQC}=150 \mu \mathrm{g} / \mathrm{mL})$ samples were run for 3 days, for a total of $n=18$ samples at each QC level. Intraday accuracy and precision were determined from the six replicates at 1 of the 3 days, and interday accuracy and precision were calculated from all 18 QC samples. The calculated mean concentration relative to the nominal concentration was used to express accuracy. The coefficient of variation $(\mathrm{CV})$ was used to estimate the precision.

\section{Pharmacokinetic and statistical analyses}

To obtain the pharmacokinetic parameters, non-compartmental analyses were performed on the measured concentrations of D-ribose using Kinetica software, version 4.4.1 (Thermo Electron Scientific, Waltham, MA, USA). The maximum observed concentration $\left(\mathrm{C}_{\max }\right)$ and the time to reach this concentration $\left(\mathrm{T}_{\max }\right)$ were determined by visual inspection of oral data. The elimination rate constant $(\mathrm{k})$ was estimated from the slope of the terminal part. The elimination half-life $\left(\mathrm{t}_{1 / 2}\right)$ was calculated as $0.693 / \mathrm{k}$. The area under the serum concentration-time curve from time 0 to the last measurable concentration $(\mathrm{t})\left(\mathrm{AUC}_{0-\mathrm{t}}\right)$ was calculated using the log-linear trapezoidal method, and the total AUC $\left(\mathrm{AUC}_{\text {total }}\right)$ was calculated as $\mathrm{AUC}_{0-\mathrm{t}}+\mathrm{C}_{\text {last }} / \mathrm{k}$. Total clearance $(\mathrm{CL})$ was calculated as dose $/ \mathrm{AUC}_{\text {total }}$. The volume of distribution at steady state $\left(\mathrm{V}_{\mathrm{ss}}\right)$ and mean residence time (MRT) were also obtained. The amount of D-ribose excreted in the urine, which was calculated from urine volume and the measured urine concentrations $\left(\mathrm{X}^{\mathrm{u}}=\mathrm{Cu}^{*} \mathrm{~V}\right)$, was used to calculate the renal clearance $\left(\mathrm{CL}_{\mathrm{r}}=\mathrm{X}_{0-\mathrm{t}}^{\mathrm{u}} / \mathrm{AUC}_{0-\mathrm{t}}\right)$. The absolute bioavailability (F) was estimated from the $\mathrm{AUC}_{\text {total }}$ data after IV and oral administrations.
Unpaired student's $t$-test was used to assess statistical differences in the pharmacokinetic parameters between the two administered doses in each route and between the two routes at the same dose. The analysis was conducted using GraphPad Prism (version 6; GraphPad Software Inc., San Diego, CA, USA). The threshold of significance was $p<0.05$.

\section{Results}

The spectrophotometric assay was found to be linear over D-ribose concentration range of 1.5625-200 $\mu \mathrm{g} / \mathrm{mL}$, with average correlation coefficients $\left(r^{2}\right)$ of 0.9981 and 0.9992 for serum and urine standards, respectively. Intraday and interday accuracies for serum were in the range of $97.4-102.1 \%$, while the precision $(\mathrm{CV})$ was in the range of $1.5-5.4 \%$ (Table 1 ). As for urine, the intraday and interday accuracies were in the range of $97-100.2 \%$, and the precision ranged from $1.2 \%$ to $8.3 \%$ (Table 1 ). This indicates the accuracy and reproducibility of the method. In addition, the stability study showed that D-ribose samples can be stored frozen at $-20^{\circ} \mathrm{C}$ for at least 2 months without degradation.

Figure 1 depicts the serum concentration-time profile of D-ribose after IV administration at doses of $420 \mathrm{mg} / \mathrm{kg}$ and $840 \mathrm{mg} / \mathrm{kg}$. After IV administration of D-ribose to rabbits, the results showed a significant threefold increase in $\mathrm{AUC}_{\text {total }}$ from $27.91 \mathrm{mg} \cdot \mathrm{min} / \mathrm{mL}$ to $100.21 \mathrm{mg} \cdot \mathrm{min} / \mathrm{mL}$ with a twofold increase in D-ribose dose from $420 \mathrm{mg} / \mathrm{kg}$ to $840 \mathrm{mg} / \mathrm{kg}$. The average elimination half-life was significantly increased from 14.46 minutes at the dose of $420 \mathrm{mg} / \mathrm{kg}$ to 24.79 minutes at the dose of $840 \mathrm{mg} / \mathrm{kg}$. The total clearance was significantly decreased from $15.3 \mathrm{~mL} \cdot \mathrm{min} / \mathrm{kg}$ with $420 \mathrm{mg} / \mathrm{kg}$ dose to $8.53 \mathrm{~mL} \cdot \mathrm{min} / \mathrm{kg}$ for the $840 \mathrm{mg} / \mathrm{kg}$ dose. No change in the volume of distribution was observed between the two doses. The pharmacokinetic parameters of IV administration are summarized in Table 2.

Figure 2 shows the serum concentration-time profile after oral administration of D-ribose. Oral data showed that D-ribose is rapidly absorbed $\left(\mathrm{T}_{\max }=36-44\right.$ minutes $)$ and

Table I Accuracy and precision of quality control samples of D-ribose in serum and urine

\begin{tabular}{|c|c|c|c|c|c|c|}
\hline & \multirow[t]{2}{*}{ Level } & \multirow[t]{2}{*}{ Nominal conc $(\mu \mathrm{g} / \mathrm{mL})$} & \multicolumn{2}{|c|}{ Intraday (\%) } & \multicolumn{2}{|c|}{ Interday (\%) } \\
\hline & & & Accuracy & CV & Accuracy & CV \\
\hline \multirow[t]{3}{*}{ Serum } & LQC & 5 & 98.3 & 4.3 & 97.4 & 5.4 \\
\hline & MQC & 15 & 100.2 & 3.0 & 99.1 & 3.3 \\
\hline & HQC & 150 & 102.1 & 1.5 & 101 & 2.8 \\
\hline \multirow[t]{3}{*}{ Urine } & LQC & 5 & 97 & 8.3 & 98.2 & 7.3 \\
\hline & MQC & 15 & 96.3 & 3.3 & 98.6 & 4.2 \\
\hline & HQC & 150 & 100.2 & 1.2 & 100.2 & 1.9 \\
\hline
\end{tabular}

Abbreviations: conc, concentration; LQC, low quality control; MQC, medium quality control; HQC, high quality control; CV, coefficient of variation. 
eliminated from the body. No significant changes in pharmacokinetic parameters were observed when oral D-ribose dose was increased from $420 \mathrm{mg} / \mathrm{kg}$ to $840 \mathrm{mg} / \mathrm{kg}$. However, a trend toward increased $\mathrm{AUC}_{\text {total }}, \mathrm{C}_{\text {max }}, \mathrm{t}_{1 / 2}$, and MRT, as well as decreased clearance, was noticed with a twofold increase in D-ribose dose. The pharmacokinetic parameters of D-ribose after oral administration are listed in Table 3.

In comparison between the two routes of administration at a given dose, oral D-ribose showed significant 3-4-fold lower $\mathrm{AUC}_{\text {total }}, 4-5$-fold higher clearance, twofold increase in MRT, and sevenfold increase in the volume of distribution as compared to the corresponding IV dose. For instance, the clearance of orally given $840 \mathrm{mg}$ D-ribose was $40.93 \mathrm{~mL} \cdot \mathrm{min} /$ $\mathrm{kg}$ compared to $8.53 \mathrm{~mL} \cdot \mathrm{min} / \mathrm{kg}$ for $840 \mathrm{mg}$ IV dose. Mean half-life was not different between the oral and IV administration at both doses of 420 and $840 \mathrm{mg} / \mathrm{kg}$. The differences in $\mathrm{AUC}_{\text {total }}$ values between groups are presented in Figure 3.

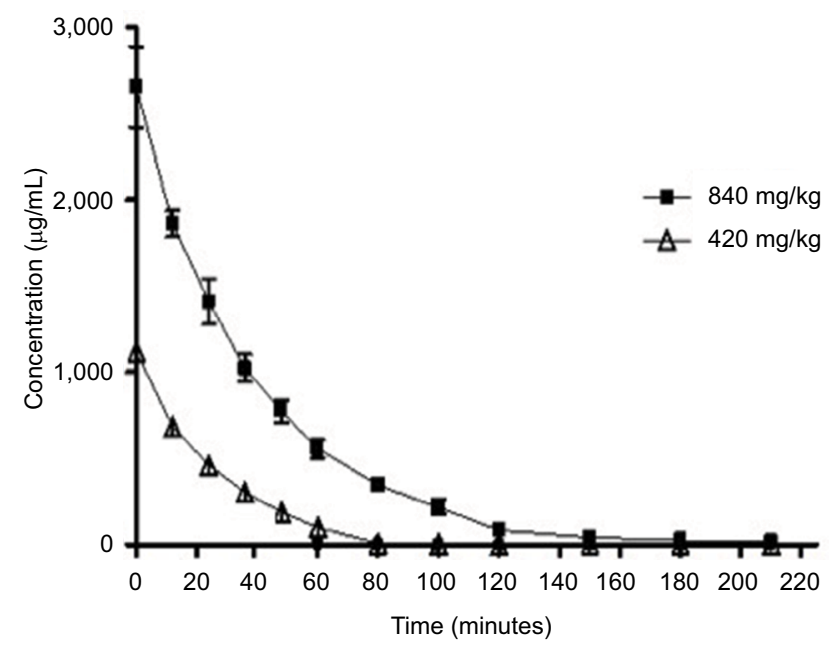

Figure I The serum concentration-time profile of D-ribose after IV administration at doses of $840 \mathrm{mg} / \mathrm{kg}$ and $420 \mathrm{mg} / \mathrm{kg}$ body weight. The values are mean $\pm \mathrm{SE}$. Abbreviations: IV, intravenous; SE, standard error.
D-ribose was recovered in the urine collected up to 210 minutes of its IV administration. The percentage of D-ribose excreted unchanged in the urine (UR) was $18 \%$ and $37.5 \%$ for the 420 and $840 \mathrm{mg} / \mathrm{kg}$ IV doses, respectively. This resulted in the mean renal clearance of $2.78 \mathrm{~mL} \cdot \mathrm{min} / \mathrm{kg}$ and 3.29 $\mathrm{mL} \cdot \mathrm{min} / \mathrm{kg}$ for the previous two doses, respectively. Urinary excretion data of D-ribose are summarized in Table 3.

\section{Discussion}

This study evaluated the pharmacokinetics of D-ribose in rabbits after single IV or oral dose administration. To our knowledge, this is the first comprehensive investigation assessing the preclinical kinetic profile of D-ribose. As indicated by results of the current study, D-ribose seems to follow a dose-dependent kinetic profile. The exposure of D-ribose increased with doubling the dose, while the clearance decreased.

The increase in D-ribose exposure observed in this study was not proportionate to the dose. Gross et al ${ }^{12}$ have shown that the steady-state concentrations $\left(\mathrm{C}_{\mathrm{ss}}\right)$ of D-ribose achieved after continuous IV infusion of 83.3 and 166.7 $\mathrm{mg} / \mathrm{kg} / \mathrm{h}$ were 7.8 and $45.3 \mathrm{mg} / 100 \mathrm{~mL}$, respectively. Also, oral administration of the same previous doses to healthy individuals resulted in Css of 4.8 and $32.6 \mathrm{mg} / 100 \mathrm{~mL} .^{12}$ Thus, doubling the dose has resulted in more than fivefold increase in the Css concentration. Similar finding has been demonstrated by Thompson et $\mathrm{al}^{13}$ who documented that administering oral doses of $2.5,5$, or $10 \mathrm{~g}$ of D-ribose to healthy subjects resulted in $\mathrm{AUC}_{0-\mathrm{t}}$ values of 6.78, 48.3, and $149 \mu \mathrm{g} \cdot \mathrm{h} / \mathrm{mL}$, respectively, suggesting that a fourfold increase in D-ribose dose yielded more than 22-fold increase in $\mathrm{AUC}_{0-\mathrm{t}}$. In our study, this nonproportionate increase in exposure was significant with IV route, but the same trend, although not statistically significant, was also observed via

Table 2 Pharmacokinetic parameters of D-ribose in rabbits following a single intravenous or oral dose administration

\begin{tabular}{|c|c|c|c|c|c|}
\hline \multirow[b]{3}{*}{$\mathrm{AUC}_{\text {total }}(\mathrm{mg} \cdot \mathrm{min}) / \mathrm{mL}$} & \multicolumn{2}{|l|}{ Intravenous (IV) } & & \multicolumn{2}{|l|}{ Oral } \\
\hline & \multirow{2}{*}{$\begin{array}{l}420 \mathbf{~ m g} / \mathbf{k g}(\mathrm{n}=4) \\
27.91 \pm 4.25\end{array}$} & \multicolumn{2}{|l|}{$840 \mathrm{mg} / \mathrm{kg}(\mathrm{n}=6)$} & $420 \mathrm{mg} / \mathrm{kg}(\mathrm{n}=3)$ & $840 \mathrm{mg} / \mathrm{kg}(\mathrm{n}=3)$ \\
\hline & & $100.21 \pm 14.7^{*}$ & $\mathrm{AUC}_{\text {total }}(\mathrm{mg} \cdot \mathrm{min}) / \mathrm{mL}$ & $8.11 \pm 3.32 * *$ & $25.36 \pm 11.92 * *$ \\
\hline $\mathrm{k}\left(\mathrm{min}^{-1}\right)$ & $0.0486 \pm 0.006$ & $0.0283 \pm 0004 *$ & $\mathrm{k}\left(\min ^{-1}\right)$ & $0.0583 \pm 0.026$ & $0.0306 \pm 0.01$ \\
\hline $\mathrm{t}_{1 / 2}(\min )$ & $14.46 \pm 1.87$ & $24.79 \pm 3.22^{*}$ & $t_{1 / 2}(\min )$ & $13.44 \pm 5.23$ & $24.52 \pm 8.89$ \\
\hline MRT (min) & $22.64 \pm 1.88$ & $38.31 \pm 3.03^{*}$ & MRT (min) & $44.53 \pm 13.9 * *$ & $54.63 \pm 6.25 * *$ \\
\hline $\mathrm{CL}(\mathrm{mL} \cdot \mathrm{min} / \mathrm{kg})$ & $15.3 \pm 2.05$ & $8.53 \pm 1.25 *$ & $\mathrm{CL}(\mathrm{mL} \cdot \mathrm{min} / \mathrm{kg})$ & $60.32 \pm 31.4^{* *}$ & $40.93 \pm 25.2^{* *}$ \\
\hline \multirow[t]{4}{*}{ Vss (mL/kg) } & $344.47 \pm 38.3$ & $326.69 \pm 51.1$ & Vss (mL/kg) & $2,438.03 \pm 577^{* *}$ & $2,266.43 \pm 1,510.4 *$ \\
\hline & & & $C_{\max }(\mu g / m L)$ & $184.6 \pm 52.1$ & $369.10 \pm 137.6$ \\
\hline & & & $\mathrm{T}_{\max }(\min )$ & $36.0 \pm 12.0$ & $44.0 \pm 13.9$ \\
\hline & & & $\mathrm{F}(\%)$ & $29.1 \pm 0.12$ & $25.3 \pm 0.19$ \\
\hline
\end{tabular}

Notes: *Significant difference from $420 \mathrm{mg} / \mathrm{kg}$ IV dose; **significant difference from the corresponding IV dose. Data are presented as mean \pm SD.

Abbreviations: $\mathrm{AUC}_{\text {total }}$, total area under the serum concentration-time curve from zero to infinite time; $k$, elimination rate constant; $t_{1 / 2}$, elimination half-life; MRT, mean residence time; $\mathrm{CL}$, clearance; $\mathrm{Vss}$, volume of distribution at steady state; $\mathrm{C}_{\max }$, maximum observed concentration; $\mathrm{T}_{\max }$, time to reach maximum concentration; $\mathrm{F}$, absolute bioavailability; IV, intravenous. 


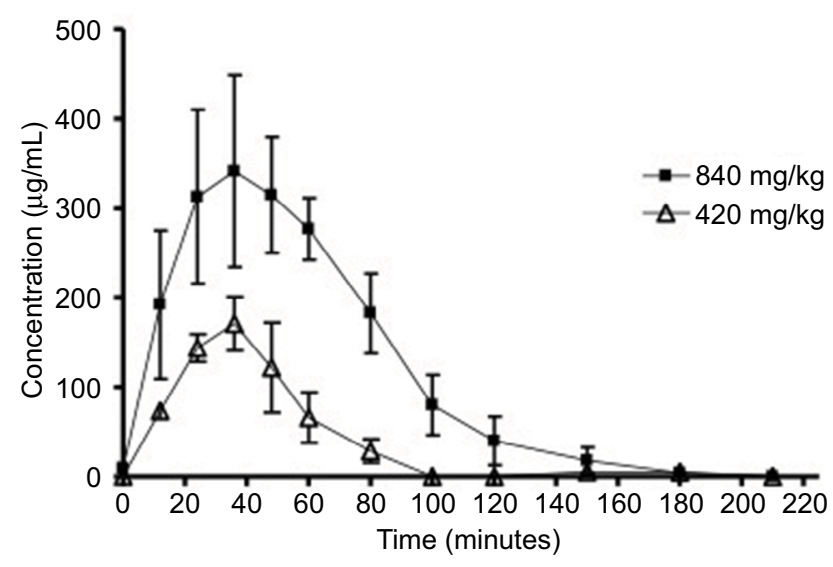

Figure 2 The serum concentration-time profile of D-ribose after oral administration at doses of $840 \mathrm{mg} / \mathrm{kg}$ and $420 \mathrm{mg} / \mathrm{kg}$ body weight. The values are mean $\pm \mathrm{SE}$. Abbreviation: SE, standard error.

Table 3 Urinary excretion data of D-ribose in rabbits after a single-dose intravenous administration

\begin{tabular}{llll}
\hline Dose & $\mathbf{C L}_{\mathbf{r}}(\mathbf{m L} \mathbf{~ m i n} / \mathbf{k g})$ & $\mathbf{X}_{{ }_{\infty}}{ }_{(\mathbf{m g})}$ & UR (ratio) \\
\hline $420 \mathrm{mg} / \mathrm{kg}(\mathrm{n}=4)$ & $2.78 \pm 0.96$ & $75.48 \pm 20.7$ & $0.180 \pm 0.05$ \\
$840 \mathrm{mg} / \mathrm{kg}(\mathrm{n}=6)$ & $3.29 \pm 1.83$ & $315.13 \pm 147.3$ & $0.375 \pm 0.18$ \\
\hline
\end{tabular}

Note: Data are presented as mean \pm SD.

Abbreviations: $X^{u}{ }_{\infty}$, cumulative D-ribose amount excreted in urine; $C L_{r}$, renal clearance; UR, percentage of D-ribose excreted unchanged in the urine.

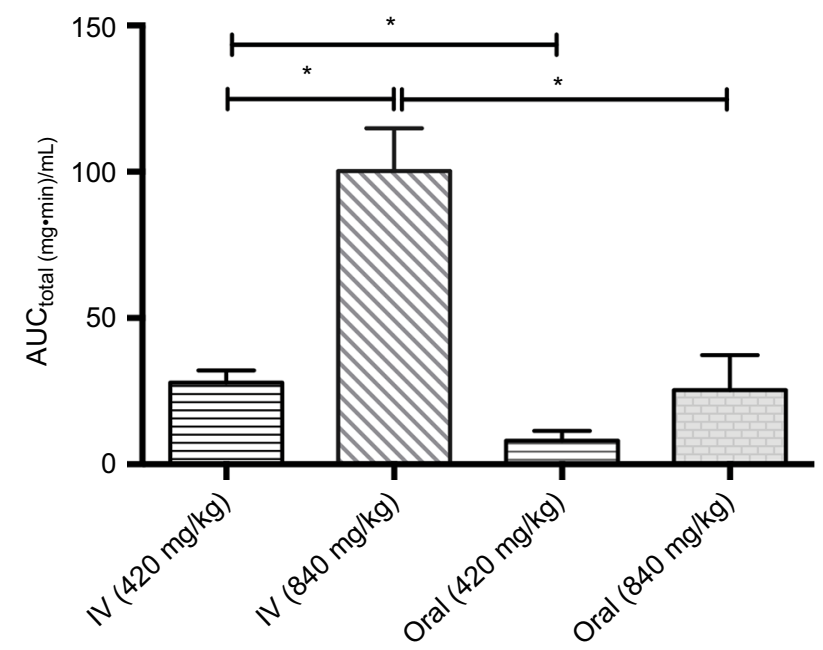

Figure 3 The total area under the serum concentration-time curve $\left(A \cup C_{\text {total }}\right)$ values for the doses given orally or intravenously to the rabbits. Data are presented as mean $\pm S D$. ${ }^{*} p<0.05$.

Abbreviation: IV, intravenous.

oral administration. The nonsignificant finding of oral data may be attributed in part to the small sample size $(n=3)$ and to the inter-rabbit variability observed. This large increase in exposure may be explained partially by the saturable metabolism of D-ribose at higher doses. ${ }^{16}$ This finding might have clinical value as exposing subjects to higher doses of D-ribose might result in nonproportional increase in the pharmacological effects and perhaps an adverse effect profile. For instance, higher episodes of diarrhea were observed when D-ribose was given orally at $200 \mathrm{mg} / \mathrm{kg} / \mathrm{h}$ versus doses of 83.3 or $166.7 \mathrm{mg} / \mathrm{kg} / \mathrm{h} .{ }^{12}$

Previous studies have shown that the levels of D-ribose fall down rapidly after IV administration in normal and diabetic human subjects. ${ }^{17}$ The time of D-ribose elimination in human to the near zero levels was about 110 minutes after a 3-20 g IV infusion dose given over 15 minutes. ${ }^{16}$ This is in accordance with our current study results, where it took about 150 minutes for D-ribose to reach near zero levels after $840 \mathrm{mg} / \mathrm{kg}$ IV bolus. The half-life of D-ribose was relatively short ranging from 13 to 25 minutes, which is in agreement with the finding of Thompson et a ${ }^{13}$ who reported half-lives over 12-20 minutes after a $2.5-15 \mathrm{~g}$ of D-ribose oral solution.

As shown in the results of this study, D-ribose plasma clearance is also dose dependent. A significant decrease in total clearance was shown with doubling the IV dose, and the same trend was also observed with oral administration. This suggests that D-ribose follows first-order kinetics at a low dose; thereafter, elimination systems seem to be saturated. The decrease in clearance was associated with a prolonged half-life from $\sim 14.5$ to 24.8 minutes with doubling the dose. These results are also in agreement with a previous observation that clearance values of 240,115 , and 83.2 $\mathrm{L} / \mathrm{h}$ were documented with oral dosing of $2.5,5$, or $10 \mathrm{~g}$, respectively. ${ }^{13}$ Thus, there appears to be no concerns about systemic accumulation.

The F of D-ribose was low (mean F=25-29\%), which may inform about the higher utilization and/or incomplete intestinal absorption of D-ribose when it is orally given. Four- to fivefold higher clearance was observed with oral versus IV dosing which may have contributed to 3-4-fold lower exposure of oral D-ribose. The increase in clearance with the oral dose was accompanied with an increase in volume of distribution. These two changes may contribute, in part, to the similar half-life of D-ribose observed via oral and IV routes.

While the metabolism via the pentose phosphate pathway accounts for the primary route of D-ribose elimination, ${ }^{16,18}$ it could also be excreted by the kidney. Renal elimination of D-ribose is mediated largely by filtration with minimal contribution to reabsorption at high doses. ${ }^{16}$ Results of this study showed that D-ribose was partially (18-38\%) recovered from urine. Previous studies have shown that an average of $21 \%$ of D-ribose was recovered in the urine after a 15 -minute D-ribose IV infusion, ${ }^{16}$ while $4.15-16.6 \%$ was recovered after oral dosing. ${ }^{12,13}$ In our study, doubling the dose has yielded a little increase in the fraction of D-ribose excreted 
in the urine and the renal clearance, which may be explained, in part, by saturation of reabsorption sites at higher doses and an increase in urinary excretion of D-ribose. However, considering the high metabolic uptake and turnover of pentose sugars, D-ribose excretion as an unchanged molecule is unlikely after typical supplemental doses. Studying urinary excretion for lower doses of D-ribose is a recommended future direction.

In conclusion, D-ribose showed a dose-dependent kinetic profile, where kinetic variables change according to the administered dosing level. It rapidly disappeared from the plasma (within less than 140 minutes). Urine recovery was partial, which could be attributed to the several metabolic pathways that pentose can undergo.

\section{Acknowledgments}

The authors would like to thank the staff of Philadelphia Biomed Product Development Centre, Amman, Jordan, and Ascent Medical Technology Fund II, LP, USA, for their financial and technical support.

\section{Disclosure}

The authors report no conflicts of interest in this work.

\section{References}

1. Berg JM, Tymoczko JL, Stryer L. Biochemistry. 3rd ed. New York: W. H. Freeman; 1998.

2. Zimmer HG. Normalization of depressed heart function in rats by ribose. Science. 1983;220:81-82.

3. Zimmer HG, Ibel H. Ribose accelerates the repletion of the ATP pool during recovery from reversible ischemia of the rat myocardium. $J \mathrm{Mol}$ Cell Cardiol. 1984;16:863-866.
4. Hudson T. D-ribose in chronic fatigue syndrome, fibromyalgia, and cardiac disease. J Nat Med. 2010;2:1-3.

5. Perlmutter NS, Wilson RA, Angello DA, Palac RT, Lin J, Brown BG. Ribose facilitates thallium-201 redistribution in patients with coronary artery disease. J Nucl Med. 1991;32:193-200.

6. Bayram M, St Cyr JA, Abraham WT. D-ribose aids heart failure patients with preserved ejection fraction and diastolic dysfunction: a pilot study. Ther Adv Cardiovasc Dis. 2015;9:56-65.

7. Nishiyama J, Ueki M, Asaga T, Chujo K, Maekawa N. Protective action of D-ribose against renal injury caused by ischemia and reperfusion in rats with transient hyperglycemia. Tohoku J Exp Med. 2009;219:215-222.

8. Ueki M, Ueno M, Morishita J, Maekawa N. D-ribose ameliorates cisplatin-induced nephrotoxicity by inhibiting renal inflammation in mice. Tohoku J Exp Med. 2013;229:195-201.

9. Teitelbaum JE, Johnson C, St Cyr J. The use of D-ribose in chronic fatigue syndrome and fibromyalgia: a pilot study. JAltern Complement Med. 2006;12:857-862.

10. Teitelbaum J, Jandrain J, McGrew R. Treatment of chronic fatigue syndrome and fibromyalgia with D-ribose - an open-label, multicenter study. Open Pain J. 2012;5:32-37.

11. Ismail ZB, Abu-Baker N, Alzoubi K, et al. Evaluation of alpha-Dribofuranose (D-ribose) toxicity after intravenous administration to rabbits. Hum Exp Toxicol. 2012;31:820-829.

12. Gross M, Reiter S, Zollner N. Metabolism of D-ribose administered continuously to healthy persons and to patients with myoadenylate deaminase deficiency. Klin Wochenschr. 1989;67:1205-1213.

13. Thompson J, Neutel J, Homer K, Tempero K, Shah A, Khankari R. Evaluation of D-ribose pharmacokinetics, dose proportionality, food effect, and pharmacodynamics after oral solution administration in healthy male and female subjects. J Clin Pharmacol. 2014;54:546-554.

14. Office of Laboratory Animal Welfare. Institutional Animal Care and Use Committee Guidebook. 2nd edition. National Institutes of Health, Bethesda, MD, USA; 2002.

15. Roe JH, Rice EW. A photometric method for the determination of free pentoses in animal tissues. J Biol Chem. 1948;173:507-512.

16. Segal S, Foley J. The metabolism of D-ribose in man. $J$ Clin Invest. 1958;37:719-735.

17. Bierman EL, Baker EM, Plough IC, Hall WH. Metabolism of D-ribose in diabetes mellitus. Diabetes. 1959;8:455-458.

18. Hiatt HH. Studies of ribose metabolism. III. The pathway of ribose carbon conversion to glucose in man. J Clin Invest. 1958;37:651-654.
Clinical Pharmacology: Advances and Applications

\section{Publish your work in this journal}

Clinical Pharmacology: Advances and Applications is an international, peer-reviewed, open access journal publishing original research, reports, reviews and commentaries on all areas of drug experience in humans. The manuscript management system is completely online and includes a very quick and fair peer-review system, which is all easy to use.

\section{Dovepress}

Visit http://www.dovepress.com/testimonials.php to read real quotes from published authors. 